\title{
VTA mTOR Signaling Regulates Dopamine Dynamics, Cocaine-Induced Synaptic Alterations, and Reward
}

\author{
Xiaojie Liu', Yan Li', Laikang Yu', Casey R Vickstrom' and Qing-song Liu*,I \\ 'Department of Pharmacology and Toxicology, Medical College of Wisconsin, Milwaukee, WI, USA
}

\begin{abstract}
Mechanistic target of rapamycin (mTOR) regulates long-term synaptic plasticity, learning, and memory by controlling dendritic protein synthesis. The mTOR inhibitor rapamycin has been shown to attenuate the behavioral effects of drugs of abuse, including cocaine. Using viral vectors to selectively delete $m T O R$ in the ventral tegmental area (VTA) in adult male mTOR ${ }^{\text {loxPlloxP }}$ mice, we investigated the role of mTOR in regulating neuronal morphology, basal synaptic transmission, dopamine dynamics, and cocaine-induced synaptic plasticity and rewarding effects. We find that targeted deletion of mTOR in the VTA had no significant effects on soma size and dendritic morphology of VTA neurons but significantly decreased dopamine release and reuptake in the nucleus accumbens (NAc) shell, a major target region. Western blot analysis revealed that mTOR deletion led to decreases in phosphorylated tyrosine hydroxylase (PTH-Ser40) levels in the VTA and dopamine transporter expression in the NAc. mTOR deletion had no significant effects on basal excitatory transmission in VTA dopamine neurons but caused an increase in GABAergic inhibition because of an increase in VTA GABAergic neuron firing. Furthermore, mTOR deletion attenuated conditioned place preference to cocaine and cocaine-induced potentiation of excitation and reduction of GABAergic inhibition in VTA dopamine neurons. Taken together, these results suggest that loss of mTOR in the VTA shifts the balance of excitatory and inhibitory synaptic transmission and decreases dopamine release and reuptake in the NAc. In addition, VTA mTOR signaling regulates cocaine-cue associative learning and cocaine-induced synaptic plasticity in VTA dopamine neurons.

Neuropsychopharmacology (20 I8) 43, I066-1077; doi: I0. I 038/npp.20 17.247; published online 29 November 2017
\end{abstract}

\section{INTRODUCTION}

The serine/threonine-protein kinase mechanistic (formerly mammalian) target of rapamycin (mTOR) is a powerful regulator of protein synthesis and controls neurodevelopment, cell growth, survival, and differentiation (Laplante and Sabatini, 2012). mTOR interacts with many proteins to form two distinct multiprotein complexes-mTORC1 and mTORC2-and controls protein synthesis by sensing nutrient and energy levels (Zoncu et al, 2011). The formation and consolidation of memories require de novo protein synthesis (Costa-Mattioli and Monteggia, 2013). mTOR controls synthesis of synaptic proteins at dendrites and regulates important brain functions such as long-term synaptic plasticity and learning and memory (Hoeffer and Klann, 2010; Costa-Mattioli and Monteggia, 2013; Huang et al, 2013). Dysfunction of mTOR signaling pathways has been implicated in diseases such as autism and epilepsy (Huber et al, 2015).

Addictive drugs usurp the neural mechanisms normally subserving reward-related learning, and exposure to drugs of abuse activates similar intracellular signaling pathways as learning and memory and is associated with similar alterations in synaptic plasticity (Nestler, 2013; Dong and

* Correspondence: Dr Q-s Liu, Department of Pharmacology and Toxicology, Medical College of Wisconsin, 870I Watertown Plank Road, Milwaukee, WI 53226, USA, Tel: + | 4I4955 8877, Fax: + | 4I4 955 6545, E-mail: qsliu@mcw.edu

Received II July 2017; revised 26 September 2017; accepted 9 October 2017; accepted article preview online 17 October 2017
Nestler, 2014). Protein synthesis is required for several druginduced adaptations, such as long-term potentiation (LTP) (Argilli et al, 2008; Yuan et al, 2013) and long-term depression (LTD) (Mameli et al, 2007; Yu et al, 2013) in the ventral tegmental area (VTA). Psychostimulants (cocaine, amphetamine), cannabinoids, opiates (morphine), and alcohol activate mTOR signaling in the mesolimbic reward circuit, and systemic injection or microinjection of the mTORC1 inhibitor rapamycin into the nucleus accumbens (NAc) attenuates drug- or alcohol-associated behaviors, such as relapse and reinforcement learning (Dayas et al, 2012; Barak et al, 2013; Neasta et al, 2014; Beckley et al, 2016). Morphine increases mTORC1 signaling but decreases mTORC2 signaling in the VTA, and Akt-mTORC2 signaling regulates morphine-induced neuroadaptations and reward tolerance (Mazei-Robison et al, 2011) and the psychomotor effects of amphetamine (Dadalko et al, 2015). Systemic or intra-NAc injections of rapamycin attenuate cocaineinduced reward and reinforcement behaviors. Specifically, intra-NAc injections of rapamycin attenuate cue-induced reinforcement and reinstatement of cocaine seeking (Wang et al, 2010; James et al, 2014, 2016). Systemic injection of rapamycin attenuates the expression of cocaine-induced locomotor sensitization and conditioned place preference (CPP) in mice (Bailey et al, 2012) or the acquisition of cocaine-induced locomotor sensitization in rats $(\mathrm{Wu}$ et al, 2011). However, the mechanisms by which mTOR inhibition attenuates the behavioral effects of cocaine remain poorly understood. 
Here, we used a Cre/LoxP system to produce VTA-specific deletion of mTOR and investigated its impact on soma size and dendritic morphology, basal synaptic transmission, dopamine dynamics, and cocaine-induced neuroadaptations and reward. AAV2-Cre-GFP was microinjected into the VTA of adult $\mathrm{mTOR}^{\text {loxP/loxP }}$ mice to induce targeted deletion of mTOR. Although mTOR exists in two distinct protein complexes, mTORC1 and mTORC2, and these can be differentially regulated by drugs of abuse (Mazei-Robison et al, 2011; Sutton and Caron, 2015), mTORC1 and mTORC2 are each known to support long-term synaptic plasticity through distinct mechanisms (Costa-Mattioli and Monteggia, 2013; Huang et al, 2013). Therefore, we sought to investigate how the dual downregulation of mTORC1 and mTORC2 signaling affects cocaine-induced neuroadaptations, dopamine dynamics, basal synaptic plasticity, and neuronal morphology in the VTA. We sought to address the following questions. First, does mTOR deletion in adult mice alter neuronal morphology in the VTA? Previous studies have shown that hyperactive mTOR signaling is associated with hypertrophy of hippocampal and cortical neurons, including increases in soma surface area, number of dendritic spines, and enlargement of dendrites (Tavazoie et al, 2005; Chow et al, 2009; Luikart et al, 2011; Weston et al, 2012; Xiong et al, 2012), whereas downregulation of Akt, an upstream activator of mTORC1, and knockout of Rictor, a component of the mTORC2 complex, decrease the soma size of VTA dopamine neurons (Mazei-Robison et al, 2011). Second, does VTA-specific mTOR deletion alter dopamine release at dopaminergic axonal terminals in the NAc? Fast-scan cyclic voltammetry (FSCV) was used to detect dopamine release in response to single or burst electrical stimulation (Yorgason et al, 2011), and the impact of mTOR deletion on dopamine release was examined. Third, does VTA-specific mTOR deletion alter basal excitatory and inhibitory synaptic transmission? Finally, does mTOR deletion alter cocaine-induced CPP and neuroadaptations? By addressing these questions, our study provides evidence that VTA mTOR signaling regulates dopamine release in the NAc, basal inhibitory synaptic transmission in the VTA, cocaine-induced neuroadaptations in VTA dopamine neurons, and drug-cue associative learning.

\section{MATERIALS AND METHODS}

\section{Animals}

$\mathrm{mTOR}^{w t / w t}$ mice and homozygous mTOR-floxed mice $\left(\mathrm{mTOR}^{\text {loxP/loxP }}\right.$, Jax stock 011009), raised and maintained on C57BL/6J background, were obtained from the Jackson Laboratory (Bar Harbor, ME). All experiments were performed on adult male mice (8-10 weeks old at the beginning of the experiments).

\section{Animal Surgery and Intra-VTA AAV Microinjections}

Male adult $\mathrm{mTOR}^{w t / w t}$ and $\mathrm{mTOR}^{\text {loxP/loxP }}$ mice (8-10 weeks old) were anesthetized and placed in a Kopf stereotaxic device. AAV2.CMV.HI.eGFP-Cre.WPRE.SV40 (the Penn Vector Core of the University of Pennsylvania) was microinjected bilaterally into the VTA via a Nanoject III Programmable Nanoliter Injector (Drummond Scientific
Company, Broomall, PA). Mice were allowed to recover for 2 weeks before experiments.

\section{Immunofluorescence Staining}

Mice were anesthetized and perfused transcardially with paraformaldehyde. Coronal VTA sections $(30 \mu \mathrm{m})$ were cut and incubated with primary and secondary antibodies. Confocal imaging was performed using a Nikon TE2000-U inverted microscope equipped with the $\mathrm{C} 1$ Plus confocal system.

\section{Microinjection of Alexa Fluor 594 into VTA Neurons}

Alexa Fluor 594 dye (Thermo Fisher Scientific, Waltham, $\mathrm{MA}$ ) (5 mM in $150 \mathrm{mM} \mathrm{KCl}$ ) was injected into AAV2-CreGFP-positive neurons in fixed brain sections via iontophoretic injection ( $-2 \mathrm{nA}$ for 3-5 min) (Dumitriu et al, 2011; Christian et al, 2017).

\section{Brain Slice Preparation}

The mouse brain was trimmed and embedded in 3\% lowmelting-point agarose, and horizontal midbrain slices or coronal striatal slices $(200 \mu \mathrm{m}$ thickness) were cut using Leica vibrating slicer VT1200s (Nussloch, Germany).

\section{Fast-Scan Cyclic Voltammetry (FSCV) Recording of Dopamine Release}

To measure dopamine release in the NAc shell with FSCV, a glass-encased cylindrical carbon fiber $(7 \mu \mathrm{m}$ diameter, Goodfellow, Oakdale, PA) microelectrode with an exposed final length of $100-150 \mu \mathrm{m}$ was lowered into the NAc shell.

\section{Western Blot Analysis}

The western blot analysis of VTA or NAc tissue samples was performed with antibodies against p-S6 (Ser 235/236), S6, p-Akt (Ser 473), p-TH (Ser 40), tyrosine hydroxylase (TH), and dopamine transporter (DAT).

\section{Slice Electrophysiology}

Horizontal midbrain slices $(200 \mu \mathrm{m}$ thick) were cut using a vibrating slicer (Leica VT1200s). EPSCs and IPSCs were recorded as we have previously described (Pan et al, 2008). AMPA/NMDA receptor (AMPAR/NMDAR) ratio was measured based on published studies (Saal et al, 2003; Liu et al, 2005).

\section{In Vivo Electrophysiology}

Mice were anesthetized and positioned in a stereotaxic frame, and craniotomies were performed to allow in vivo single-unit recordings of VTA GABAergoc neurons. To confirm cell type and electrode placement, neurons were juxtacellularly labeled with neurobiotin.

\section{Conditioned Place Preference}

Cocaine CPP was based on published procedures (Vialou et al, 2012; Liu et al, 2016). 


\section{Statistics}

Data are presented as mean \pm SEM. Synaptic currents were analyzed using Mini-analysis (Synaptosoft). CPP scores were calculated as the time spent in the cocaine-conditioned chamber minus that in the saline-conditioned chamber. Data sets were compared with either Student's $t$-test or two-way ANOVA followed by Tukey's post hoc analysis using Sigmaplot 11.2. For unpaired data that do not follow a normal distribution, the Mann-Whitney $U$-test was used, and data are reported as median (interquartile range). Results were considered to be significant at $P<0.05$.

Materials and methods are described in detail in the Supplementary Materials and Methods.

\section{RESULTS}

\section{AAV-Mediated Deletion of mTOR in the VTA}

To delete mTOR in the VTA, we injected AAV2-CreGFP into the VTA bilaterally in mTOR-floxed mice $\left(\mathrm{mTOR}^{\text {loxP/loxP }}\right)$. AAV2-Cre-GFP was also bilaterally injected into the VTA of $\mathrm{mTOR}^{w t / w t}$ mice to serve as a control. The effectiveness of the AAV2-Cre-GFP was validated by our previous studies (Zhong et al, 2014). At 2 weeks after the AAV2-Cre-GFP injection, mice were killed and mTOR expression in the VTA was determined by immunofluorescence labeling using antibodies against mTOR and TH. GFP fluorescence was directly visualized, where it was observed predominantly in the nuclei of infected neurons. This nuclear localization is consistent with previous studies, and occurs because GFP is directly fused to Cre and a nuclear localization signal from SV40 (Kaspar et al, 2002; Zhong et al, 2014). Both $\mathrm{TH}^{+}$dopamine neurons and $\mathrm{TH}^{-}$nondopamine neurons (putative GABAergic neurons) were infected by the AAVs. AAV2-Cre-GFP deleted mTOR in both dopamine neurons and non-dopamine neurons in the VTA in $\mathrm{mTOR}^{\text {loxp/loxp }}$ mice $(n=4$ mice; Figure 1a) but mTOR expression was abundant in $\mathrm{mTOR}^{\text {wt/wt }}$ mice $(n=3$ mice; Figure 1a). mTORC1 phosphorylates and activates its downstream effector S6 kinase, whereas the Ser-473 site of Akt is a substrate for mTORC2 phosphorylation (Laplante and Sabatini, 2012). Phospho-S6 (p-S6) expression in the VTA was significantly decreased in $\mathrm{mTOR}^{\text {toxP/loxP }}$ mice as shown by immunohistochemical staining $(n=2$ mice; Figure 1b) and western blot analysis compared with $\mathrm{mTOR}^{w t / w t}$ mice $\left(17.7 \pm 2.9 \%, t_{8}=18.0, \quad P<0.001, \quad n=5\right.$ mice; Figure $1 \mathrm{c}$ and d). Similarly, phospho-Akt (p-Akt Ser$473)$ levels in the VTA were decreased in $\mathrm{mTOR}^{\text {loxp/loxP }}$ mice $\left(15.4 \pm 4.1 \%, t_{8}=12.8, P<0.001, n=5\right.$ mice; Figure $1 \mathrm{c}$ and d). Thus, mTOR deletion decreased mTORC1 and mTORC2 signaling in the VTA.

\section{mTOR Deletion Did Not Alter the Morphology of VTA Neurons}

Genetic mutations that lead to hyperactive mTORC1 signaling cause neuronal hypertrophy in the hippocampus and cortex, as shown by increases in the size of somata and dendrites, and the number of dendritic spines (Tavazoie et al, 2005; Luikart et al, 2011; Weston et al, 2012; Xiong et al, 2012). It was of interest to investigate whether mTOR deletion alters the morphology of VTA neurons. We injected Alexa Fluor $594(5 \mathrm{mM})$ into GFP-positive neurons in the VTA in fixed brain sections from $\mathrm{mTOR}^{\text {loxp/loxp }}$ and $\mathrm{mTOR}^{w t / w t}$ mice that received intra-VTA injection of AAV2-Cre-GFP 2 weeks prior (Supplementary Figure S1). We found that the surface area of somata, dendritic length, dendritic thickness, and number of dendrites per neuron in VTA neurons were not significantly different between $\mathrm{mTOR}^{\text {wt/wt }}$ and $\mathrm{mTOR}^{\text {loxP/loxP }}$ mice $(n=13-17$ cells $/ 4-5$ mice; $P>0.05$; Supplementary Figure S1). For technical reasons, we did not identify whether the dye-injected neurons were dopamine neurons or non-dopamine neurons. Prior TH immunostaining of VTA sections significantly retarded subsequent Alexa 594 diffusion into dendrites of injected neurons, whereas post hoc $\mathrm{TH}$ immunostaining after Alexa 594 injection caused significant loss of the Alexa 594 at dendrites, in particular, distal dendrites. Permeabilization of the cell membrane required for $\mathrm{TH}$ antibody incubation may be responsible for the dye loss at distal dendrites. Thus, mTOR deletion in the VTA did not result in apparent changes in neuronal morphology.

\section{VTA-Specific mTOR Deletion Decreased Dopamine Release and Reuptake in the NAc Shell}

Dopamine is synthesized by dopamine neurons in the VTA and is axonally transported for release in the NAc. Using FSCV to detect evoked dopamine release in striatal slices from $\mathrm{mTOR}^{w t / w t}$ and $\mathrm{mTOR}^{\text {loxP/loxP }}$ mice, we investigated whether mTOR deletion in the VTA altered dopamine release in the NAc shell. We chose to record from the NAc shell for the following reasons. Both microdialysis and in vivo FSCV have shown that natural rewards (palatable food, sucrose) increase dopamine release in the shell but not the core, whereas aversive tastes decrease dopamine release in the shell (reviewed by Saddoris et al, 2013). In addition, cocaine administration causes a greater increase in dopamine transients in the shell compared with the core (Aragona et al, 2008). FSCV recordings were made blindly to mouse genotype, and dopamine release was detected by a carbonfiber microelectrode placed in the NAc shell (Yorgason et al, 2011). Dopamine release was evoked by a single electrical stimulus pulse or a train of stimuli (5 pulses) at 10,30 , or $50 \mathrm{~Hz}$ at a fixed intensity $(250 \mu \mathrm{A}, 0.1 \mathrm{~ms}$ duration). The average peak concentration of dopamine in the NAc shell was decreased in $\mathrm{mTOR}^{\text {loxP/loP }}$ mice at single-pulse and 10, 30 , and $50 \mathrm{~Hz}$ 5-pulse stimulation (1 pulse: $t_{15}=3.6$, $P=0.003 ; \quad 10 \mathrm{~Hz}: \quad t_{15}=4.9, \quad P<0.001 ; \quad 30 \mathrm{~Hz}: \quad t_{15}=9.0$, $P<0.001 ; 50 \mathrm{~Hz}: t_{15}=11.0, P<0.001 ; n=3-4$ mice; Figure $2 \mathrm{a}$ and $\mathrm{b})$. Thus, mTOR deletion in the VTA decreased dopamine release in its target region, the NAc shell.

Additionally, VTA mTOR deletion prolonged the decay of dopamine responses in the NAc shell (Figure $2 \mathrm{a}$ and $\mathrm{c}$ ). Dopamine reuptake by DAT is the primary mechanism responsible for extracellular dopamine clearance in the brain (Giros et al, 1996). The decay time constant $(\tau)$ of the falling phase of dopamine transients is a function of the dopamine uptake rate (Yorgason et al, 2011). We found that the decay time constant $\tau$ of the dopamine responses in $\mathrm{mTOR}^{\text {loxP/loxP }}$ mice was significantly prolonged compared with that of $\mathrm{mTOR}^{w t / w t}$ mice at all stimulation frequencies (1 pulse: $t_{15}=2.3, P=0.037 ; 10 \mathrm{~Hz}: t_{15}=5.7, P<0.001 ; 30 \mathrm{~Hz}: t_{15}=4.2$, 
a
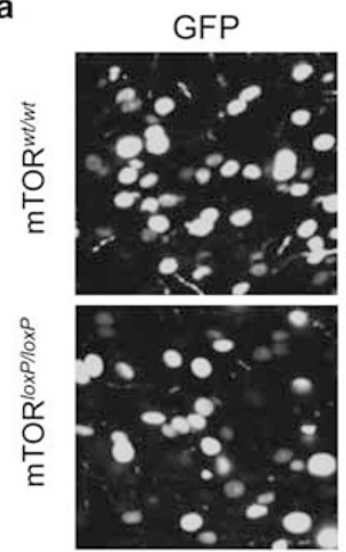

b
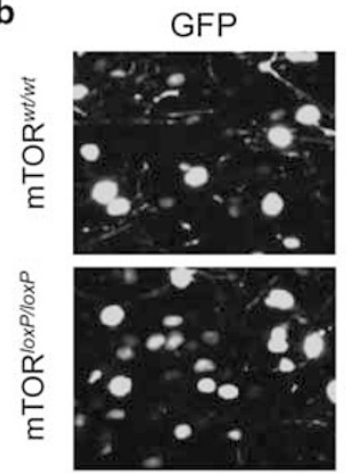

C

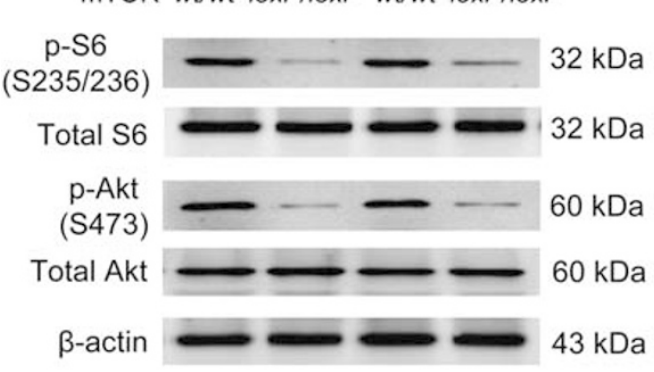

$\mathrm{TH}$
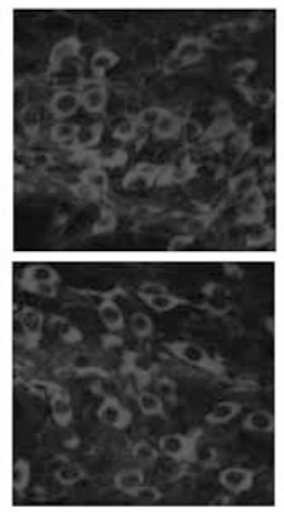

$\mathrm{TH}$
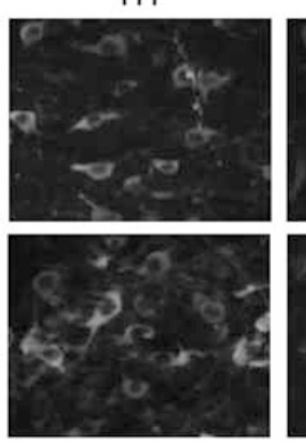

\section{Overlay}
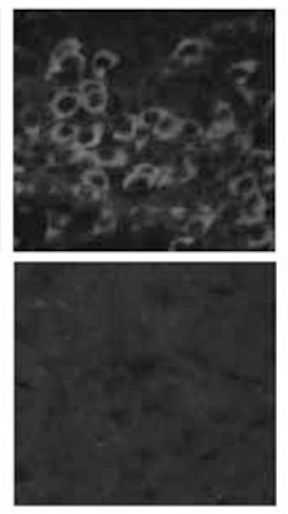

p-S6
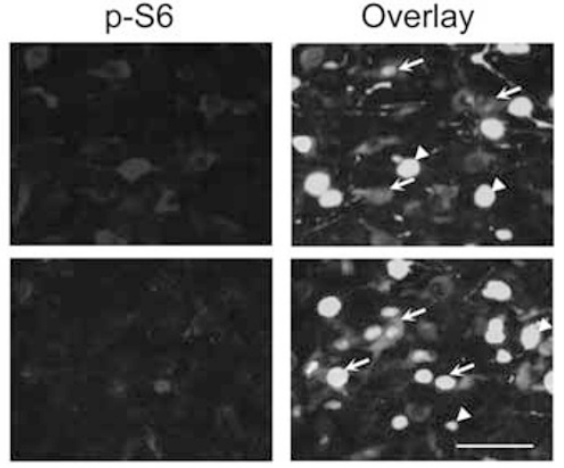

d

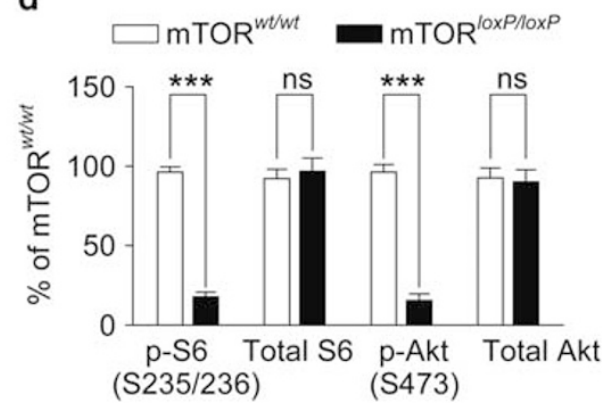

Figure I AAV2-Cre-GFP-mediated deletion of mTOR in the VTA. VTA immunostaining following mTOR deletion. (a) Immunofluorescence labeling indicates that mTOR expression remains in TTOR $^{\text {wt/wt }}$ mice $(n=3)$ but not mTOR ${ }^{\text {loxPlloxP }}$ mice $(n=4) 2-3$ weeks after intra-VTA injection of AAV2-CreGFP. Scale bar, $50 \mu \mathrm{m}$. Arrows: representative dopamine neurons; arrowheads, representative non-dopamine neurons. (b) Immunofluorescence labeling indicates that mTOR deletion decreased phosphorylated S6 kinase (p-S6 S235/236) expression in the VTA ( $n=2$ mice). (c, d) Western blots (c) and normalized data (d) revealed that mTOR deletion led to decreases in p-S6 S235/236 (mTORCI-dependent) and p-Akt S473 (mTORC2-dependent) in the VTA ( $n=5$ mice/group; **** $P<0.00$ I, ns, not significant).

$P<0.001 ; 50 \mathrm{~Hz}: t_{15}=2.5, P=0.024$; Figure $\left.2 \mathrm{c}\right)$. These results suggest that loss of mTOR impaired dopamine clearance in the NAc shell.

What might be the mechanisms for mTOR deletioninduced decreases in dopamine release and reuptake? $\mathrm{TH}$ is the rate-limiting enzyme for dopamine synthesis (Dunkley et al, 2004). TH phosphorylation at Ser40 increases the catalytic activity of $\mathrm{TH}$ and thereby dopamine synthesis (Dunkley et al, 2004). We examined whether mTOR deletion altered protein levels of phosphorylated TH at Ser40 (p-TH S40) and total TH in VTA tissue samples using western blot analysis. There was a significant decrease in the protein level of p-TH S40 in $\mathrm{mTOR}^{\text {loxP/loxP }}$ mice $(58.2 \pm 9.8 \%, n=6$ mice) compared with that of $\mathrm{mTOR}^{w t / w t}$ mice $\left(t_{10}=2.8, P=0.018\right)$, whereas total TH remained unchanged $\left(t_{10}=0.6, P=0.591\right)$. The $\mathrm{p}$-TH S40/total TH ratio was decreased in $\mathrm{mTOR}^{\text {loxP/loxP }}$ mice ( $56.0 \pm 6.8 \%, t_{10}=3.5, P=0.006$; Figure $3 a$ and $\left.c\right)$. The decrease in $\mathrm{p}$-TH $\mathrm{S} 40$ in $\mathrm{mTOR}^{\text {loxP/loxP }}$ mice suggests a decrease in dopamine synthesis that may explain why dopamine responses are decreased in $\mathrm{mTOR}^{\text {loxP/loxP }}$ mice.

DAT is expressed on the plasma membrane of axons from dopaminergic neurons in both the NAc shell and core (Nirenberg et al, 1997). We also examined whether mTOR deletion in the VTA altered DAT protein levels in the NAc. Western blot analysis indicated that DAT protein levels were significantly decreased in $\mathrm{mTOR}^{\text {loxP/loxP }}$ mice $(41.3 \pm 11.3 \%$, $n=6$ mice) compared with those of $\mathrm{mTOR}^{w t / w t}$ mice $\left(t_{10}=4.0, P=0.002\right.$; Figure $3 \mathrm{~b}$ and $\left.\mathrm{c}\right)$. The decrease in DAT 

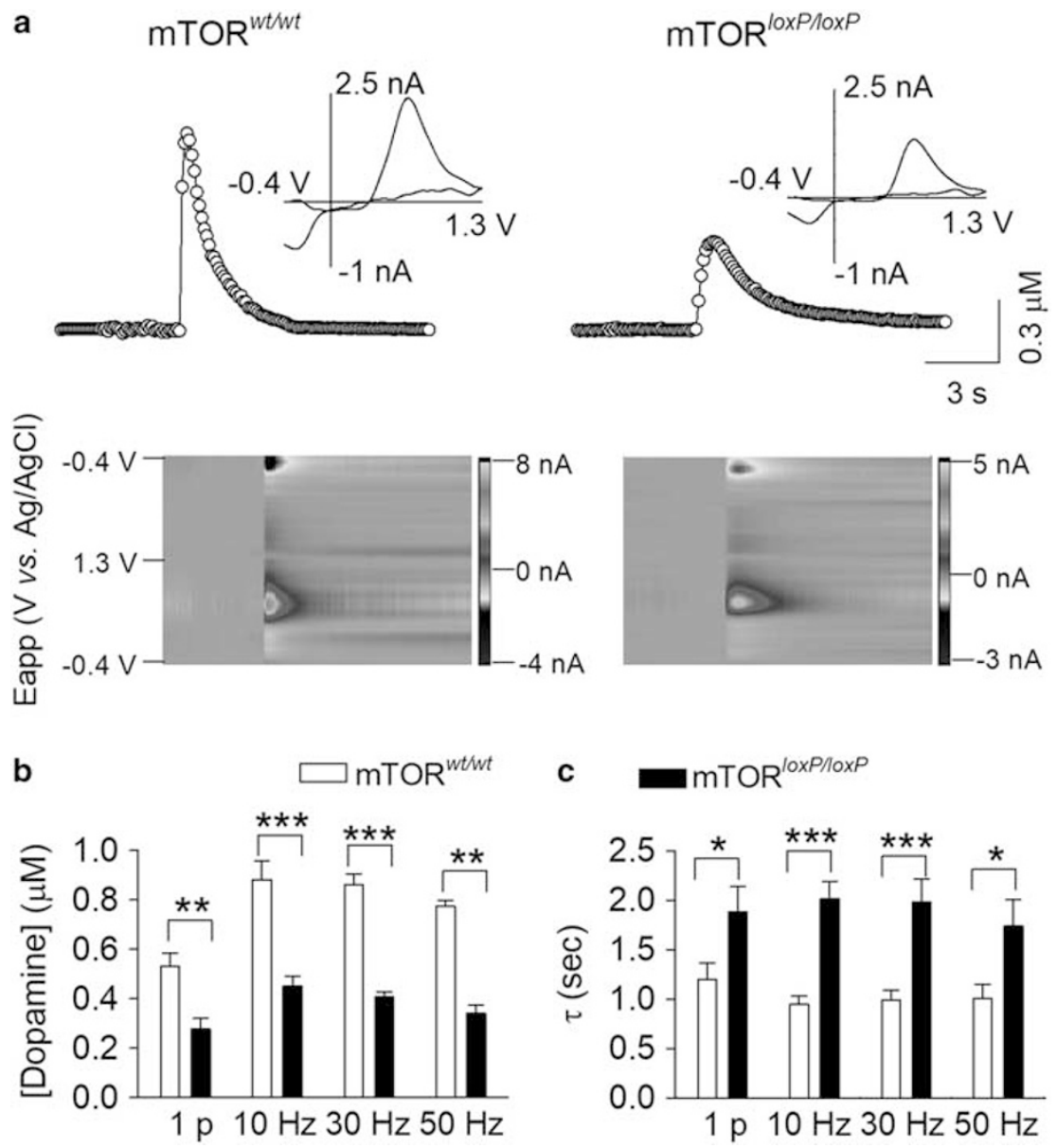

C
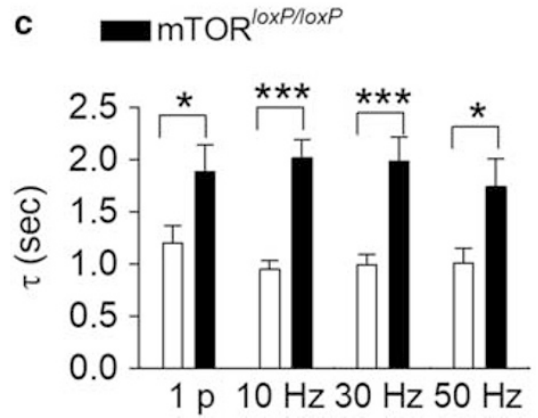

Figure 2 VTA-specific mTOR deletion significantly decreased dopamine release and reuptake in the NAc shell. (a) Concentration trace (top) and color plot (bottom) for dopamine release triggered by electrical stimulation of the NAc shell in $\mathrm{mTOR}^{\text {wtwt }}$ and $\mathrm{mTOR}^{\text {loxPlloxp }}$ mice at 2 weeks after intra-VTA injection of AAV2-Cre-GFP. Top, representative traces showing the concentration of dopamine $(\mu M)$ over time in response to 5 -pulse electrical stimulation at $30 \mathrm{~Hz}$. Inset shows characteristic dopamine voltammogram. Bottom, corresponding color plot depicting the voltammetric data with time on the $x$ axis, applied scan potential (Eapp) on the $y$ axis, and background-subtracted faradaic current shown on the $z$ axis in pseudocolor. Dopamine can be identified by an oxidation peak (green) at $+0.6 \mathrm{~V}$ and a smaller reduction peak (black) at $-0.2 \mathrm{~V}$. (b) Summarized data showing the average peak concentration of dopamine in the NAc shell in response to single-pulse and 5 -pulse stimulation $\left(10,30\right.$, and $50 \mathrm{~Hz}$ ). Dopamine release was significantly decreased in $\mathrm{mTOR}^{\text {loxPlloxP }}$ mice at single-pulse, and 10,30 , and $50 \mathrm{~Hz}$ stimulations $\left({ }^{*} * P<0.01\right.$, **** $\left.P<0.001, n=8-9\right)$ compared with $\mathrm{mTOR}^{w \mathrm{w} / \mathrm{wt}}$ mice. (c) Summarized data showing that decay time constants $(\tau)$ of dopamine transients were significantly prolonged in $\mathrm{mTOR}^{\text {loxPlloxP }}$ mice at single-pulse and 10,30 , and $50 \mathrm{~Hz}$ stimulations $(* P<0.05, * * * P<0.00 \mathrm{I}, n=8-9$ from $3-4$ mice) compared with $\mathrm{mTOR}^{\text {wtiwt }}$ mice. A full color version of this figure is available at the Neuropsychopharmacology journal online.

likely explains why the decay time constant of dopamine release in the NAc was prolonged in mTOR $^{\text {loxP/loxP }}$ mice.

\section{Effects of VTA-Specific mTOR Deletion on Excitatory and Inhibitory Synaptic Transmission in VTA Dopamine Neurons}

We examined whether mTOR deletion altered basal excitatory and inhibitory synaptic transmission in VTA dopamine neurons. $\mathrm{mTOR}^{\text {wt/wt }}$ and $\mathrm{mTOR}^{\text {loxp } / l o x P}$ mice received intraVTA injections of AAV2-Cre-GFP. At 2 weeks following the injection, mice were killed and midbrain slices were prepared. The identification of dopamine neurons and recordings of miniature excitatory postsynaptic currents (mEPSCs) and spontaneous EPSCs (sEPSCs) are detailed in the Supplementary Methods. There was no significant change in the mean frequency $\left(t_{23}=0.01, P=0.992\right)$ or amplitude $\left(t_{23}=1.4, P=0.176\right)$ of mEPSCs in VTA dopamine neurons between $\mathrm{mTOR}^{w t / w t}$ and $\mathrm{mTOR}^{\text {loxP/loxP }}$ slices (Supplementary Figure S2). The mean frequency $\left(t_{24}=0.7, P=0.493\right)$ and amplitude $\left(t_{23}=0.9, P=0.365\right)$ of sEPSCs were not significantly different between $\mathrm{mTOR}^{\text {wt/wt }}$ and $\mathrm{mTOR}^{\text {loxPlloxP }}$ slices (Supplementary Figure S2). Together, these results indicate that genetic deletion of mTOR did not alter basal excitatory synaptic transmission in VTA dopamine neurons.

We also examined whether mTOR deletion altered basal inhibitory synaptic transmission in VTA dopamine neurons. We found that mTOR deletion had no significant effects on the mean frequency $\left(t_{28}=0.8, P=0.443\right)$ and mean amplitude $\left(t_{28}=0.7, \quad P=0.463\right)$ of mIPSCs (Supplementary Figure S3). In contrast, mTOR deletion significantly increased the frequency $\left(t_{25}=2.4, P=0.026\right)$ but not the amplitude $\left(t_{25}=0.7, P=0.477\right)$ of sIPSCs (Supplementary Figure S3). Thus, mTOR deletion enhances basal inhibitory synaptic transmission by increasing the frequency of sIPSCs in VTA dopamine neurons. 
a

mTOR wt/wt loxP/loxP wt/wt loxP/loxP

p-TH (S40)

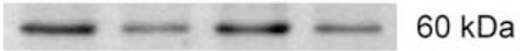

Total TH

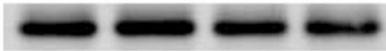

$60 \mathrm{kDa}$

$\beta$-actin

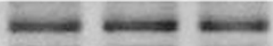

$43 \mathrm{kDa}$

b

mTOR wt/wt loxP/loxP wt/wt loxP/loxP

DAT

$80 \mathrm{kDa}$

$\beta$-actin

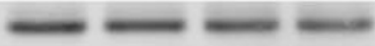

$43 \mathrm{kDa}$

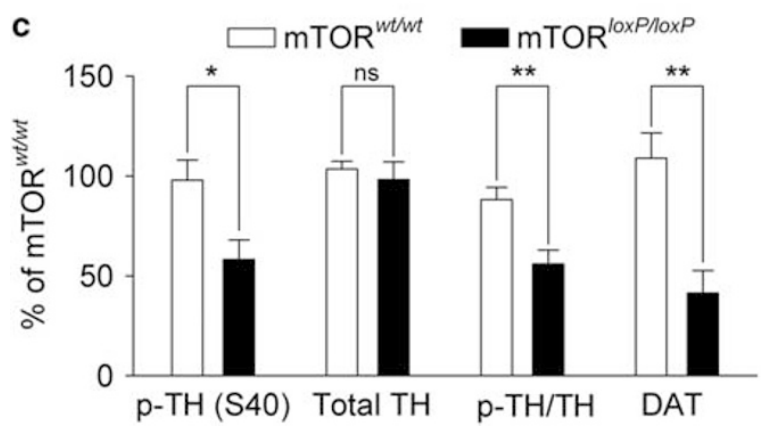

Figure 3 VTA-specific mTOR deletion decreased p-TH S40 protein expression in the VTA and decreased DAT protein expression in the NAc. (a) Representative western blots for $\mathrm{p}-\mathrm{TH}(\mathrm{S} 40)$, total $\mathrm{TH}$, and $\beta$-actin in VTA homogenates prepared from $m T R^{w t / w t}$ and $m T \mathrm{RR}^{\text {loxP/loxP }}$ mice after intra-VTA injection of AAV2-Cre-GFP. (b) Representative western blots for DAT and $\beta$-actin in NAc homogenates prepared from $\mathrm{mTOR}^{\text {wt }}$ wt and mTOR ${ }^{\text {loxPlloxP }}$ mice after intra-VTA injection of AAV2-Cre-GFP. (c) Summarized data indicate that the protein expression of $\mathrm{p}-\mathrm{TH}$ (S40) was significantly decreased in the VTA of mTOR ${ }^{\text {loxplloxP }}$ mice compared with $\mathrm{mTOR}^{\text {wt } / \text { t }}$ mice $(* P<0.05)$. Total $\mathrm{TH}$ protein expression was not significantly altered $(P>0.05)$. Therefore, the $\mathrm{P}-\mathrm{TH} / \mathrm{TH}$ ratio was significantly decreased in the VTA in $m T O R^{\text {loxPlloxP }}$ mice $(* * P<0.01)$. VTA-specific deletion of mTOR significantly decreased DAT protein expression in the NAc compared with mTOR ${ }^{\text {wt }}{ }^{\text {wt }}$ mice (**P $<0.01, n=6$ mice for each comparison). Immunoreactivity was normalized to $\beta$-actin and is presented as a percentage of that of $\mathrm{mTOR}^{\text {wt/wt }}$ mice.

\section{mTOR Deletion Increased In Vivo AP Firing of VTA GABAergic Neurons}

VTA dopamine neurons receive GABAergic inhibitory synaptic inputs from local interneurons as well as from medium spiny neurons (MSNs) in the NAc (Bocklisch et al, 2013). The increase in sIPSC frequency in $\mathrm{mTOR}^{\text {loxP/loxP }}$ mice might be attributable to an increase in AP firing in GABAergic VTA neurons. To test this possibility, we made single-unit recordings of AP firing in vivo in $\mathrm{mTOR}^{w t / w t}$ and $\mathrm{mTOR}^{\text {loxPlloxP }}$ mice that received intra-VTA injection of AAV2-Cre-GFP 2 weeks before the recordings. Mice were anesthetized with urethane and in vivo single-unit recordings were performed. VTA GABA neurons were identified by short-duration ( $<1 \mathrm{~ms})$, nonbursting, high-frequency $(>10 \mathrm{~Hz})$ spikes (Steffensen et al, 1998) (Figure 4a). These firing characteristics could be distinguished from those of VTA dopamine neurons that exhibit a broad triphasic extracellular action potential with a width $>2 \mathrm{~ms}$ and a relatively slow firing rate $(<10 \mathrm{~Hz})$ (Ungless et al, 2004). Furthermore, a subset of VTA GABAergic neurons were validated by juxtacellular labeling with neurobiotin and post hoc TH immunostaining to verify that neurobiotinlabeled neurons were TH negative (Ungless et al, 2004; Chaudhury et al, 2013) (Figure 4b). We found that the frequency of AP firing of GABAergic neurons was significantly increased in $\mathrm{mTOR}^{\text {loxP/loxP }}$ mice compared with that of $\mathrm{mTOR}^{w t / w t}$ mice $\left(t_{27}=2.2, P=0.035\right.$; Figure $\left.4 \mathrm{a}\right)$.

We also recorded AP firing in cell-attached mode in GABA neurons in VTA slices, identified by the criteria described in the Supplementary Materials and Methods. The AP frequency was significantly increased in VTA GABA neurons in slices from $\mathrm{mTOR}^{\operatorname{loxp} P / \operatorname{lox} P}$ mice (median frequency: $4.4 \mathrm{~Hz}(3.6-5.2 \mathrm{~Hz}), n=11)$ compared with that of $\mathrm{mTOR}^{\text {wt/wt }}$ mice (median frequency: $2.4 \mathrm{~Hz}(2.1-4.2 \mathrm{~Hz}$ ), $n=12$; Mann-Whitney $U=30.0, P=0.029$ ). What might be the mechanisms for the increase in AP firing of VTA GABAergic neurons? Voltage-gated $\mathrm{K}^{+}$channels control the repolarization of APs, and partial blockade of $\mathrm{K}^{+}$channels significantly increases AP firing in GABAergic interneurons (Ding et al, 2011). We therefore examined whether voltagegated $\mathrm{K}^{+}$currents were altered following $\mathrm{mTOR}$ deletion. Whole-cell voltage clamp recordings were made from VTA GABAergic neurons (Figure 4c), and voltage-gated $\mathrm{K}^{+}$ currents were induced by depolarization steps (from $-60 \mathrm{mV}$ to $+10 \mathrm{mV}, 10 \mathrm{mV}$ increments, $1 \mathrm{~s}$ duration). We found that mTOR deletion significantly decreased the peak amplitude of $\mathrm{K}^{+}$currents at voltage steps to $-30 \mathrm{mV}$ or greater (Figure 4c). Thus, this mTOR deletion-induced decrease in voltage-gated $\mathrm{K}^{+}$currents may contribute to the increase in AP firing in VTA GABAergic neurons, and the enhancement of GABAergic inhibition to VTA dopamine neurons.

\section{VTA-Specific Deletion of mTOR Attenuated Cocaine- Induced CPP}

We examined whether deletion of mTOR in the VTA altered cocaine-induced CPP. $\mathrm{mTOR}^{\text {loxP/loxp }}$ and $\mathrm{mTOR}^{\text {wt/wt }}$ mice that received intra-VTA AAV2-Cre-GFP injections 2 weeks prior underwent saline and cocaine conditioning. Mice that exhibited unconditioned place preference $(\geqslant 180 \mathrm{~s})$ during the pretest were excluded from further experiments $(n=3)$. The remaining mice did not exhibit baseline bias $(P>0.05$; Figure $5 \mathrm{a})$. Then, cocaine $(15 \mathrm{mg} / \mathrm{kg}$, i.p.) or saline place conditioning was conducted twice daily for 2 days (see Materials and Methods). At $24 \mathrm{~h}$ after the last pairing, CPP was tested without any drug or vehicle administration. Twoway ANOVA revealed that genotype $\left(\mathrm{F}_{(1,38)}=4.8, P=0.035\right)$ and cocaine conditioning $\left(\mathrm{F}_{(1,38)}=31.1, P<0.001\right)$ had significant effects on the preference score, and there was a significant interaction between genotype and cocaine conditioning $\left(\mathrm{F}_{(1,38)}=6.9, P=0.012\right.$; Figure $\left.5 \mathrm{~b}\right)$. Tukey's post hoc tests showed that cocaine conditioning led to a significant increase in the preference score $(317 \pm 30 \mathrm{~s})$ in $\mathrm{mTOR}^{w t / w t}$ mice $(P<0.001)$, and that this increase was significantly attenuated in $\mathrm{mTOR}^{\text {loxP/loxP }}$ mice $(156 \pm 37 \mathrm{~s}$; $P<0.001$; Figure $5 b$ ). Thus, mTOR deletion from the VTA attenuates cocaine-cue associative learning.

During place conditioning, locomotor activity in the conditioning chambers was tracked by infrared photobeam breaks. We compared locomotor activity in saline- or cocaine-conditioned $\mathrm{mTOR}^{w t / w t}$ and $\mathrm{mTOR}^{\operatorname{loxP} / l o x P}$ mice over the course of cocaine and saline conditioning sessions. 
a

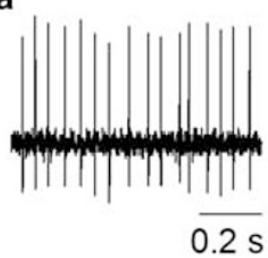

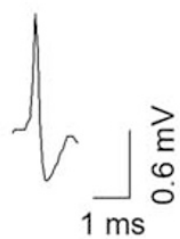

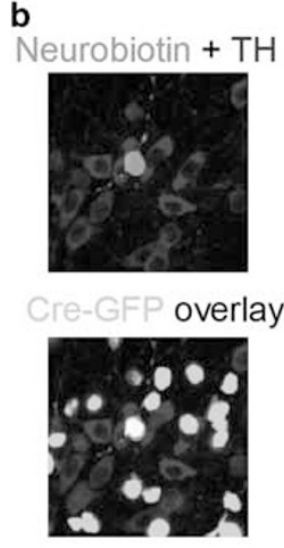

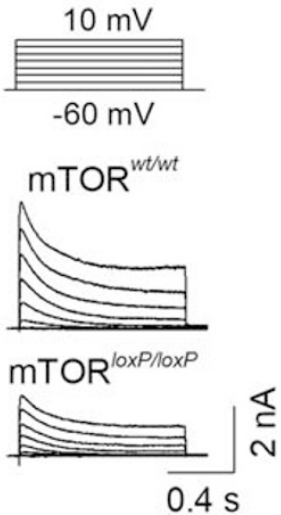

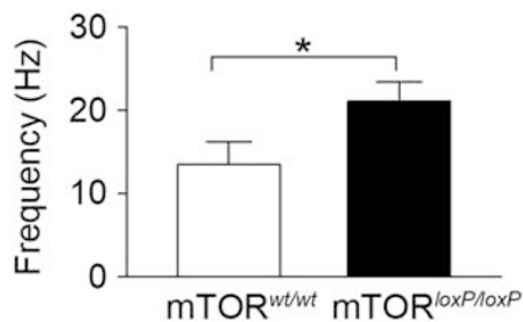

mTOR ${ }^{\text {wtwt }}$ mTOR ${ }^{\text {loxPloxP }}$

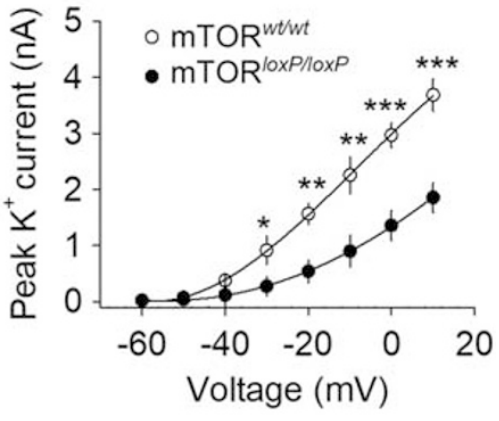

Figure 4 VTA-specific mTOR deletion increased in vivo AP firing of VTA GABAergic neurons. (a) mTOR deletion in the VTA led to an increase in the frequency of action potential firing by VTA GABAergic neurons ( $P=0.035, n=14-15$ cells from $5-6$ mice). GABAergic neurons were identified by shortduration ( $<\mathrm{I} \mathrm{ms}$ ), nonbursting, high-frequency $(>10 \mathrm{~Hz}$ ) spikes. (b) Neurobioton labeling of recorded VTA neuron and post hoc immunostaining for TH and GFP allows identification of Cre-expressing GABAergic neurons from in vivo single-unit recordings. (c) mTOR deletion in the VTA decreased peak voltagegated $\mathrm{K}^{+}$currents at voltage steps to $-30 \mathrm{mV}$ or greater $(* P<0.05$, ** $P<0.01$, **** $P<0.00 \mathrm{I}, \mathrm{n}=1 \mathrm{I}-12$ from $3-4$ mice).

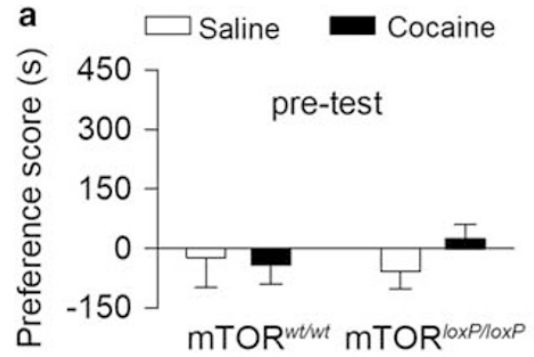

C

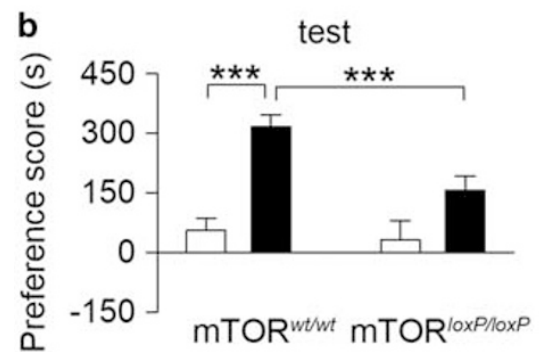

$$
\begin{aligned}
& \longrightarrow \mathrm{mTOR}^{\text {wt/wt }} / \text { saline } \\
& \longrightarrow \mathrm{mTOR}^{\text {loxP/loxP}} / \text { saline } \\
& \longrightarrow \mathrm{mTOR}^{\text {wt/wt }} / \text { cocaine } \\
& \square \mathrm{mTOR}^{\text {loxP/oxP }} / \text { cocaine }
\end{aligned}
$$

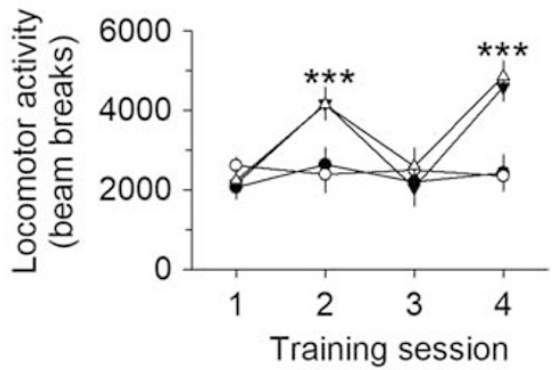

Figure 5 Genetic deletion of mTOR in the VTA attenuated cocaine CPP. (a) mTOR ${ }^{\text {wt/wt }}$ and $m T O R^{\text {loxplloxp }}$ mice that received intra-VTA injection of AAV2-Cre-GFP exhibited no unconditioned place preference during the pretest $\left(P>0.05, n=8-12\right.$ mice). (b) Cocaine CPP was attenuated in mTOR ${ }^{\text {loxP } / l o x P}$

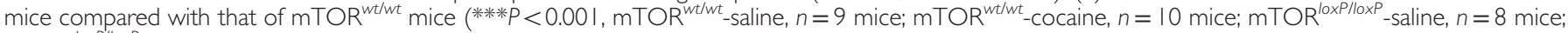
$\mathrm{mTOR}^{\text {loxPlloxP}}$-cocaine, $n=12$ mice). (c) Compared with saline conditioning, cocaine significantly increased locomotor activity over the 2 days of place conditioning ( $* * * P<0.00 I ; n=8-12$ ), and locomotor activity was not significantly different among different genotypes $(P=0.74 I ; n=8-12$ mice).

Locomotor activity was analyzed with a mixed ANOVA that included between-subject factors of place conditioning and genotype and the within-subject factor of conditioning sessions. Cocaine conditioning significantly increased locomotor activity over the 2 days of place conditioning
$\left(F_{(1,77)}=51.2, P<0.001\right)$, locomotor activity was not significantly different among the different genotypes $\left(\mathrm{F}_{(1,77)}=0.1, \quad P=0.944\right)$, and there was no significant interaction between place conditioning and genotypes $\left(F_{(1,77)}=0.3, P=0.612\right.$, Figure $\left.5 c\right)$. Thus, cocaine-induced 
increases in locomotor activity were not significantly different between $\mathrm{mTOR}^{\text {wt/wt }}$ and $\mathrm{mTOR}^{\text {loxP/loxP }}$ mice. These results suggest that the reduction of CPP scores in $\mathrm{mTOR}^{\text {loxP/ }}$ loxp mice could not be attributed to the secondary consequence of changes in locomotor activity.

\section{mTOR Deletion Blocked Cocaine-Induced Potentiation of Excitatory Synaptic Transmission on VTA Dopamine Neurons}

Single or repeated i.p. cocaine injections lead to an increase in AMPAR/NMDAR ratio in VTA dopamine neurons (Ungless et al, 2001; Borgland et al, 2004; Liu et al, 2005; Mameli et al, 2009; Liu et al, 2016). We examined whether cocaine CPP was associated with changes in the AMPAR/ NMDAR ratio in VTA dopamine neurons, and if so, whether these effects were altered by mTOR deletion. At 1 day after the CPP test, the mice shown in Figure 5 were killed and midbrain slices were prepared. The AMPAR/NMDAR ratio was measured in VTA dopamine neurons in slices prepared from these four groups of mice. Two-way ANOVA showed that mTOR deletion $\left(\mathrm{F}_{(1,31)}=13.1, P=0.001\right)$ and cocaine conditioning $\left(\mathrm{F}_{(1,31)}=9.5, P=0.005\right)$ had significant effects on the AMPAR/NMDAR ratio, and there was a significant interaction between $\mathrm{mTOR}$ deletion and place conditioning $\left(\mathrm{F}_{(1,31)}=10.0, P=0.004\right.$; Figure $6 \mathrm{a}$ and $\left.\mathrm{b}\right)$. Tukey's post hoc tests showed that cocaine conditioning significantly increased the AMPAR/NMDAR ratio $(P<0.001)$ in $\mathrm{mTOR}^{w t /}$ ${ }^{w t}$ mice compared with that of saline conditioning, whereas the increase was absent in $\mathrm{mTOR}^{\text {loxP/loxP }}$ mice $(P<0.001)$. These results indicate that $\mathrm{mTOR}$ deletion blocked the cocaine conditioning-induced increase in the AMPAR/ NMDAR ratio in VTA dopamine neurons.

We then examined whether mEPSCs in the VTA were altered by cocaine conditioning and mTOR deletion. Two-way ANOVA showed that mTOR deletion and cocaine conditioning had significant effects on the frequency ( $\mathrm{mTOR}$ deletion, $\mathrm{F}_{(1,53)}=6.5$, $P=0.014$; cocaine conditioning, $\left.\mathrm{F}_{(1,53)}=8.4, P=0.005\right)$ and amplitude (mTOR deletion, $\mathrm{F}_{(1,53)}=14.9, P<0.001$; cocaine conditioning, $\left.\mathrm{F}_{(1,53)}=7.7, P=0.008\right)$ of mEPSCs, and there were significant interactions between $\mathrm{mTOR}$ deletion and cocaine conditioning on the frequency $\left(\mathrm{F}_{(1,53)}=4.1, P=0.048\right.$; Figure $6 \mathrm{c}$ and $\mathrm{d})$ and amplitude $\left(\mathrm{F}_{(1,53)}=4.3, P=0.004\right.$; Figure $6 \mathrm{c}$ and $\left.\mathrm{e}\right)$ of mEPSCs. Tukey's post hoc tests showed that cocaine conditioning significantly increased the frequency and amplitude of mEPSCs in $\mathrm{mTOR}^{w t / w t}$ mice compared with saline conditioning $(P<0.001)$, whereas the increases were absent in $\mathrm{mTOR}^{\text {loxP/lox }}$ mice (frequency, $P=0.002$; amplitude, $P<0.001$ ). Thus, although mTOR deletion did not alter basal mEPSCs, it blocked cocaine conditioning-induced increases in the frequency and amplitude of mEPSCs in VTA dopamine neurons.

\section{VTA-Specific mTOR Deletion Attenuated Cocaine CPP- Induced Reduction of GABAergic Inhibition}

Cocaine exposure in vivo leads to a decrease in the frequency and amplitude of IPSCs in VTA dopamine neurons (Liu et al, 2005; Bocklisch et al, 2013). We examined whether cocaine conditioning and mTOR deletion altered sIPSCs in VTA dopamine neurons ex vivo. At 1 day after the CPP test, the mice were killed and midbrain slices were prepared. sIPSC in VTA dopamine neurons were measured in slices prepared from saline- or cocaine-conditioned $\mathrm{mTOR}^{w t / w t}$ or
$\mathrm{mTOR}^{\text {loxp/loxP }}$ mice. We found that mTOR deletion and cocaine conditioning had significant effects on the mean frequency of sIPSCs (mTOR deletion: $F_{(1,50)}=31.9$, $P<0.001$; cocaine conditioning: $\mathrm{F}_{(1,50)}=36.5, P<0.001$; mTOR deletion $\times$ cocaine conditioning interaction: $\mathrm{F}_{(1,50)}=4.2, P=0.045$; Figure $7 \mathrm{a}$ and $\mathrm{b}$ ) and mean amplitude of sIPSCs (mTOR deletion: $\mathrm{F}_{(1,50)}=8.4, P=0.006$; cocaine conditioning: $\mathrm{F}_{(1,50)}=5.9, P=0.019$; mTOR deletion $\times$ cocaine conditioning interaction: $\mathrm{F}_{(1,50)}=5.1, P=0.029$; Figure $5 \mathrm{a}$ and $\mathrm{c})$. Tukey's post hoc tests indicated that cocaine conditioning significantly decreased the frequency $(P=0.008$; Figure $7 \mathrm{~b})$ and the mean amplitude $(P=0.002$; Figure $7 \mathrm{c}$ ) of sIPSCs in $\mathrm{mTOR}^{w t / w t}$ mice. However, mTOR deletion blocked the cocaine conditioning-induced decrease in the amplitude $(P<0.001$; Figure $7 \mathrm{c})$ of sIPSCs. Although cocaine conditioning did decrease sIPSC frequency in mTOR knockout mice, sIPSC frequency was significantly greater in mTOR knockout mice compared with $\mathrm{mTOR}^{\text {wt/wt }}$ mice following cocaine conditioning $(P=0.014$; Figure $7 \mathrm{~b})$. Together, these results indicate that cocaine CPP led to a decrease in GABAergic inhibition to VTA dopamine neurons in $\mathrm{mTOR}^{w t / w t}$ mice, and this decrease was attenuated in $\mathrm{mTOR}^{\text {loxP/loxP }}$ mice.

\section{DISCUSSION}

In the present study, we used AAV2-Cre-GFP to delete mTOR in adult $\mathrm{mTOR}^{\text {loxP/loxP }}$ mice, thus allowing us to specifically investigate the dual role of $\mathrm{mTORC} 1$ and $\mathrm{mTORC} 2$ signaling in adult neurons by avoiding potential effects of mTOR deletion on neuronal development. We first examined the impact of loss of mTOR on neuronal morphology, dopamine dynamics, and basal synaptic plasticity in the VTA, and then examined whether mTOR deletion altered cocaine-induced CPP and neuroadaptations. We showed that VTA mTOR signaling regulates dopamine dynamics, basal inhibitory synaptic transmission, and cocaine-induced neuroadaptations and reward.

\section{mTOR Deletion Did Not Significantly Alter the Soma Size of VTA Neurons}

Hyperactive mTOR signaling leads to increases in the soma surface area and number of dendritic spines (Tavazoie et al, 2005; Luikart et al, 2011; Weston et al, 2012; Xiong et al, 2012). AAV-Cre-mediated deletion of Rictor, a critical component of mTORC2, causes an $\sim 20 \%$ decrease in the surface area of dopamine neuron somata (Mazei-Robison et al, 2011). We found that mTOR deletion did not significantly affect the soma size, nor the dendritic morphology of VTA neurons, as shown by Alexa 594 dye injection. However, we must acknowledge that only a relatively small numbers of neurons were sampled in the present study, and some dendritic branches were severed during tissue sectioning, and thus the current approach may not be sensitive enough to detect subtle differences of neuronal morphology induced by mTOR deletion.

\section{mTOR Deletion Decreased Dopamine Release and Reuptake}

The mTORC1 inhibitor rapamycin induces the formation of autophagic vacuoles in dopaminergic axons, leading to 
a
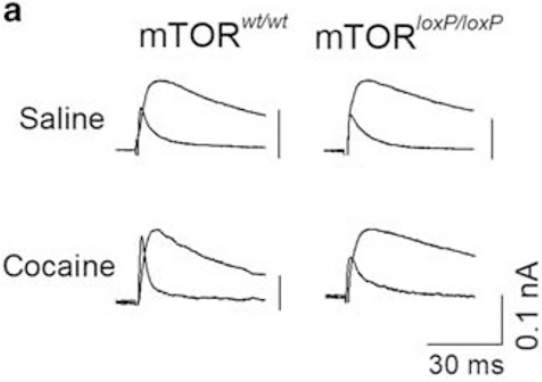

C
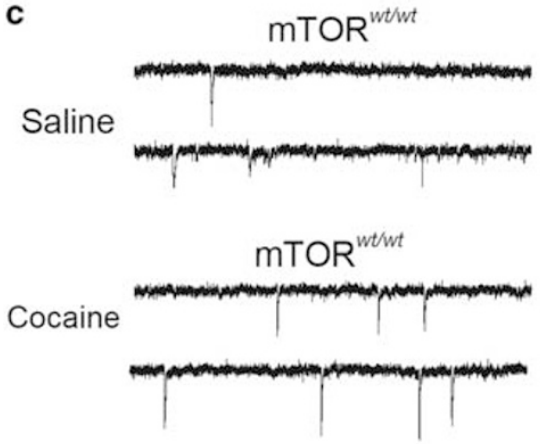

d

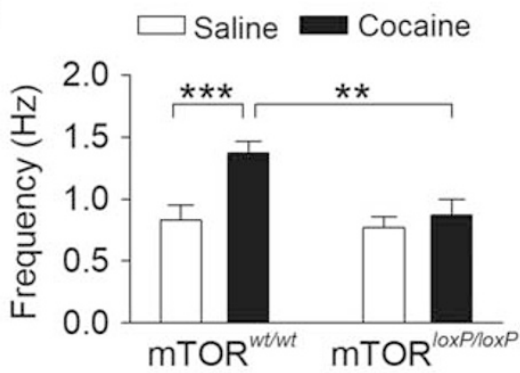

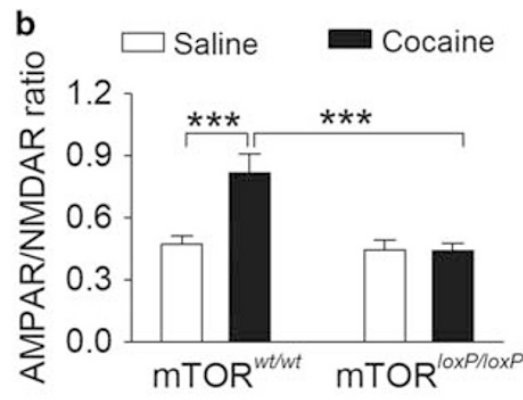
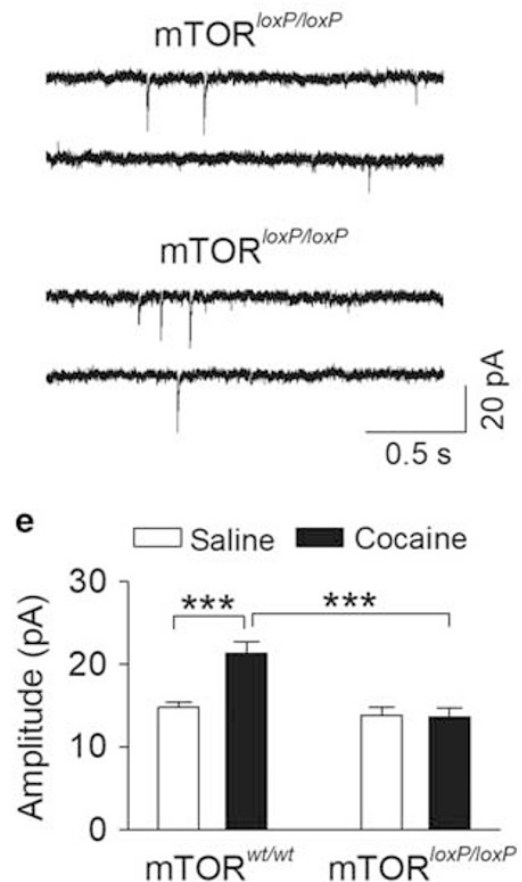

Figure 6 Genetic deletion of mTOR in the VTA blocked the increase in AMPAR/NMDAR ratio induced by a single cocaine injection in vivo. (a) Representative AMPAR- and NMDAR-mediated evoked EPSCs recorded from VTA dopamine neurons in saline- or cocaine-conditioned mTOR ${ }^{\text {wt }}$ wt and $\mathrm{mTOR}^{\text {loxP/loxP }}$ mice 2 weeks after intra-VTA injection of AAV2-Cre-GFP. (b) Cocaine conditioning significantly increased the AMPAR/NMDAR ratio in $\mathrm{mTOR}^{\text {wt } / \text { wt }}$ slices (**** $P<0.001, n=7-8$ ), whereas this increase was absent in $\mathrm{mTOR}^{\text {loxPlloxP }}$ slices $(* * * * P<0.001, n=8-9)$. (c) Representative mEPSCs recorded from VTA dopamine neurons in saline- or cocaine-conditioned mTOR ${ }^{\text {wt/wt }}$ and mTOR $^{\text {loxPlloxP }}$ mice. (d, e) Cocaine place conditioning significantly increased the frequency and amplitude $(* * * P<0.001, n=13-15)$ of $m E P S C s$ in $m T O R^{\text {wt }}{ }^{\text {wt }}$ slices, whereas these increases were blocked in $m T O R^{\text {loxPlloxP }}$ slices (** $P=0.002$, **** $<<0.001, n=\mid 4-15)$. Each data set was obtained from 3-4 mice.

decreases in axonal profile volumes, synaptic vesicle numbers, and evoked dopamine release (Hernandez et al, 2012), whereas a decrease in mTORC2 signaling in the VTA was shown to decrease dopamine release in the NAc (Mazei-Robison et al, 2011). Consistent with these findings, VTA-specific mTOR deletion led to a decrease in the mean peak amplitude of evoked dopamine transients in the NAc shell either by single or burst stimulation at high frequencies. Western blot analysis indicated that protein levels of phosphorylated $\mathrm{TH}$ at Ser40 were decreased with mTOR deletion in the VTA, despite unaltered total TH. As phosphorylation at Ser40 increases the catalytic activity of TH (Dunkley et al, 2004) — the rate-limiting enzyme for dopamine synthesis-this large decrease in p-TH S40 may significantly decrease dopamine synthesis and contribute to the decreased amplitude of evoked dopamine transients. Additionally, rapamycin treatment causes a decrease in the mTORC1dependent maintenance of dopamine synaptic vesicles (Hernandez et al, 2012). Thus, reductions in mTOR signaling, either through deletion or inhibition, may result in a decrease in releasable vesicular dopamine through parallel deficits in dopamine synthesis and vesicular maintenance.

The DAT-mediated reuptake of dopamine is one of the key factors that shape the decay kinetics of dopamine transients (Giros et al, 1996). We found that the decay time constants of evoked dopamine transients, which are a reliable measure for assessing dopamine uptake (Yorgason et al, 2011), were significantly prolonged in VTA mTOR-deleted mice compared with that of wild-type mice at all stimulation frequencies. Consistent with this, we found that protein levels of DAT in the NAc were substantially decreased following mTOR deletion in the VTA. As DAT is the primary mechanism for extracellular dopamine clearance in the brain (Giros et al, 1996), the retardation of dopamine clearance is likely attributable to the observed decrease in DAT expression. Interestingly, the selective mTORC1 inhibitor rapamycin did not significantly alter the decay of evoked dopamine transients in striatal slices (Hernandez et al, 2012). One possibility is that loss of mTORC2 but not 
a
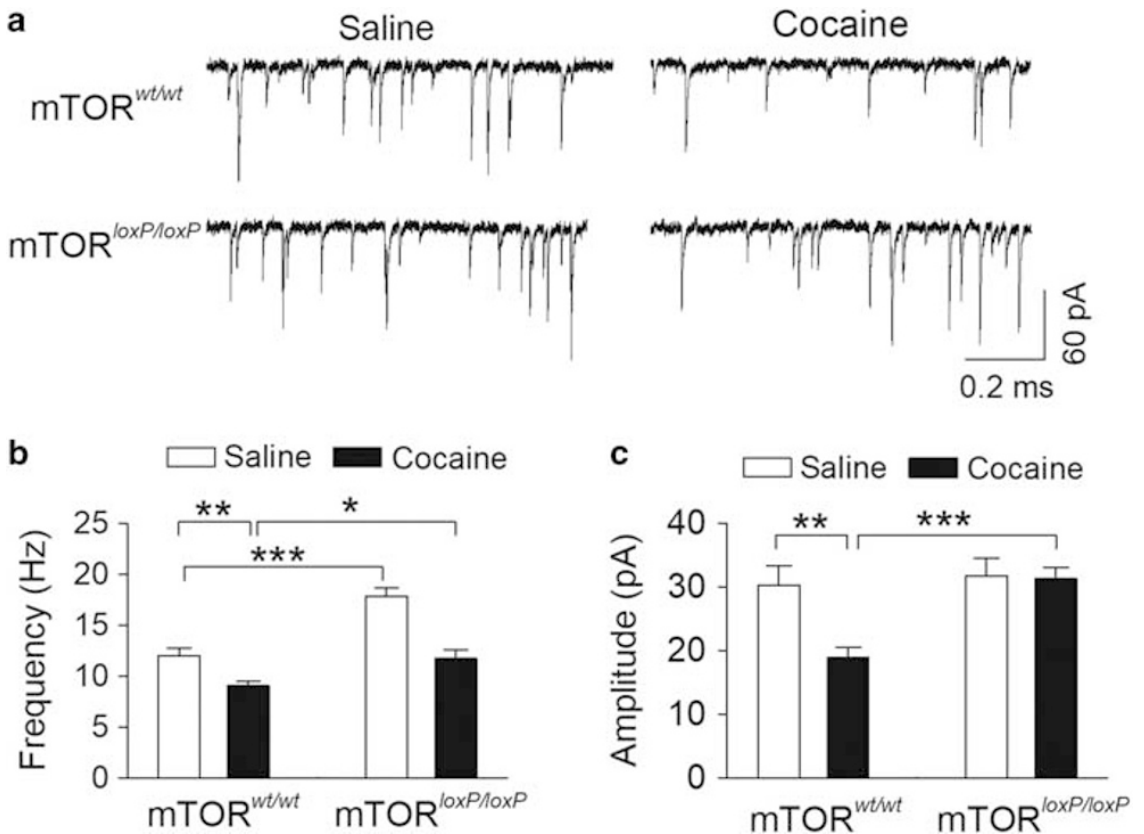

Figure 7 Genetic deletion of mTOR in the VTA attenuated the reduction of GABAergic inhibition to dopamine neurons induced by cocaine CPP. (a) Representative sIPSCs recorded from VTA dopamine neurons in slices prepared from saline- or cocaine-conditioned $\mathrm{mTOR}^{\mathrm{wt} / \mathrm{wt}}$ and $\mathrm{mTOR}$ (loxP/loxP mice after intra-VTA injection of AAV2-Cre-GFP. (b) Mean sIPSC frequency in $\mathrm{mTOR}^{\text {loxP/loxP }}$ mice is significantly increased compared with $m$ TOR ${ }^{\text {wt/wt }}$ mice with saline conditioning (*** $P<0.001, n=12-13$ ). Mean sIPSC frequency was significantly decreased in cocaine-conditioned mTOR ${ }^{\text {wt } / w t}$ mice compared with that of saline-conditioned mice ( $\left.{ }^{*} P=0.008, n=13-14\right)$, and this decrease was blocked by mTOR deletion $(* P=0.014, n=12-13)$. (c) Mean sIPSC amplitude was significantly decreased in cocaine-conditioned $m T O R^{\text {wt } / \text { t }}$ mice $(* * P=0.002, n=12-13)$, and this decrease was blocked in $m T O R^{\text {loxPlloxP }}$ mice (***P $<0.001$, $n=13-14)$. Each data set was obtained from 3-4 mice.

mTORC1 may be responsible for the retardation of dopamine clearance.

\section{Effects of mTOR Deletion on Basal Synaptic Transmission in the VTA}

Several studies indicate mTOR hyperactivation causes an increase in basal excitatory transmission in most cases but a decrease in basal inhibitory transmission in the hippocampus (Tavazoie et al, 2005; Luikart et al, 2011; Weston et al, 2012; Xiong et al, 2012; Bateup et al, 2013). Here we found that the mean frequency and amplitude of mEPSCs and sEPSCs in VTA dopamine neurons were not significantly different between wild-type mice and $\mathrm{mTOR}^{\text {loxP/loxP }}$ mice, suggesting that mTOR deletion in the VTA had no significant effects on basal excitatory transmission. In contrast, mTOR deletion in the VTA led to an increase in the mean frequency of sIPSCs without significantly altering mIPSCs or sIPSC amplitude. mIPSCs are produced by the quantal release of GABA from single vesicles, whereas sIPSCs are largely action potential driven. These results suggest that mTOR deletion leads to an increase in GABAergic neuron firing but has no significant effect on the quantal release of GABA nor the expression and/ or function of $\mathrm{GABA}_{\mathrm{A}}$ receptors. Consistent with this idea, we found that $\mathrm{mTOR}$ deletion caused a significant increase in AP firing in VTA GABAergic neurons in vivo and in vitro, and that voltage-gated $\mathrm{K}^{+}$currents were significantly decreased in VTA GABAergic neurons following mTOR deletion. $\mathrm{K}^{+}$channels control the repolarization of APs, and blockers that produce partial blockade of $\mathrm{K}^{+}$channels significantly increase AP firing in GABAergic interneurons (Ding et al, 2011). The mTOR deletion-induced decrease in voltage-gated $\mathrm{K}^{+}$currents may contribute to the increase in AP firing in VTA GABAergic neurons. Overall, mTOR deletion leads to an increase in inhibitory synaptic input in VTA dopamine neurons, likely through an enhancement of VTA GABAergic neuronal firing.

\section{Effects of mTOR Deletion on Cocaine-Induced CPP and Synaptic Alterations}

Several previous studies have demonstrated roles for mTOR signaling in regulating drug- or alcohol-associated behaviors. Trefoil factor 3 (TFF3), a brain-synthesized peptide thought to activate mTOR signaling, can enhance cocaine-induced mTOR activation, hyperlocomotion, and CPP (Luo et al, 2016). Inhibition of GSK-3, an mTORC1 inhibitor, disrupts the reconsolidation of cocaine-associated reward memories (Shi et al, 2014). Systemic or intra-NAc injection of rapamycin has been shown to attenuate many behavioral effects of drug and alcohol abuse (Dayas et al, 2012; Neasta et al, 2014; Beckley et al, 2016), including for cocaine (Wang et al, 2010; Wu et al, 2011; Bailey et al, 2012; James et al, 2014, 2016). Systemic injections of rapamycin before CPP testing, but not during the conditioning phase, attenuated CPP in mice, suggesting that rapamycin blocked the expression, but not the acquisition of cocaine CPP (Bailey et al, 2012).

Modulation of dopamine, glutamate, and GABA synaptic transmission might contribute to the mTOR deletion-induced disruption of cocaine CPP. First, VTA mTOR deletion caused a reduction of stimulus-evoked dopamine release in one of its primary target regions, the NAc shell. This reduced dopamine release may be the result of reduced phosphorylation of $\mathrm{TH}$. mTOR deletion also increased the decay time constant of dopamine responses, likely because of decreased dopamine 
uptake resulting from a reduction in DAT expression. This decreased dopamine synthesis and availability of binding sites for cocaine might dampen the cocaine-induced elevation of dopamine levels in the NAc. Second, although VTA mTOR deletion had no effects on basal excitatory synaptic transmission, it blocked cocaine-induced increases in mEPSCs and AMPAR/NMDAR ratio. It has been shown that GluA1 knockout prevents cocaine-induced increases in the AMPAR/ NMDAR ratio in VTA dopamine neurons and cocaine CPP (Dong et al, 2004). Cocaine exposure activates mTORC1 signaling in the VTA and NAc, and rapamycin blocks the cocaine-induced increase in GluA1 levels in the NAc (Wu et al, 2011; James et al, 2014). These data appear to support a model in which cocaine exposure activates mTORC1 signaling, leading to insertion of synaptic GluA1, potentiation of excitatory transmission in the VTA, and formation of cocaine-cue associative memories.

Finally, VTA mTOR deletion led to an enhancement of sIPSCs in VTA dopamine neurons that can be attributed to an increase in AP firing in VTA GABA neurons. It has been shown that reduced mTORC2 signaling can cause downregulation of $\mathrm{K}^{+}$channel subunits in the VTA (MazeiRobison et al, 2011). We suspect that the mTOR deletioninduced reduction of $\mathrm{mTOC} 2$ signaling leads to a decrease in voltage-gated $\mathrm{K}^{+}$currents in VTA GABA neurons and an increase in AP firing. In addition, mTOR deletion blocked the cocaine-induced reduction of sIPSC amplitude in VTA dopamine neurons. Although cocaine reduced sIPSC frequency in VTA dopamine neurons from mTOR-deleted mice, sIPSC frequency did not differ between saline-treated wild-type mice and cocaine-treated, mTOR-deleted mice. Thus, mTOR signaling is necessary for the cocaine-induced potentiation of glutamatergic excitation, and may also contribute to the reduction of GABAergic inhibition in VTA dopamine neurons. However, as both mTORC1 and mTORC2 signaling are disrupted following mTOR deletion, future work is necessary to parse out the roles of mTORC1 and mTORC2 in regulating dopamine dynamics and cocaine-induced synaptic plasticity and behavior.

\section{FUNDING AND DISCLOSURE}

This work was supported by the NIH Grants DA035217 and MH101146 to Q-SL, and by F30MH115536 to CRV. It was also partially funded through the Research and Education Initiative Fund, a component of the Advancing a Healthier Wisconsin Endowment at the Medical College of Wisconsin. CRV is a member of the Medical Scientist Training Program at the Medical College of Wisconsin that is supported by training grant NIGMS T32-GM080202. The authors declare no conflict of interest.

\section{REFERENCES}

Aragona BJ, Cleaveland NA, Stuber GD, Day JJ, Carelli RM, Wightman RM (2008). Preferential enhancement of dopamine transmission within the nucleus accumbens shell by cocaine is attributable to a direct increase in phasic dopamine release events. J Neurosci 28: 8821-8831.

Argilli E, Sibley DR, Malenka RC, England PM, Bonci A (2008). Mechanism and time course of cocaine-induced long-term potentiation in the ventral tegmental area. J Neurosci 28: 9092-9100.
Bailey J, Ma D, Szumlinski KK (2012). Rapamycin attenuates the expression of cocaine-induced place preference and behavioral sensitization. Addict Biol 17: 248-258.

Barak S, Liu F, Ben Hamida S, Yowell QV, Neasta J, Kharazia V et al (2013). Disruption of alcohol-related memories by mTORC1 inhibition prevents relapse. Nat Neurosci 16: 1111-1117.

Bateup HS, Johnson CA, Denefrio CL, Saulnier JL, Kornacker K, Sabatini BL (2013). Excitatory/inhibitory synaptic imbalance leads to hippocampal hyperexcitability in mouse models of tuberous sclerosis. Neuron 78: 510-522.

Beckley JT, Laguesse S, Phamluong K, Morisot N, Wegner SA, Ron D (2016). The first alcohol drink triggers mTORC1-dependent synaptic plasticity in nucleus accumbens dopamine D1 receptor neurons. J Neurosci 36: 701-713.

Bocklisch C, Pascoli V, Wong JC, House DR, Yvon C, de Roo M et al (2013). Cocaine disinhibits dopamine neurons by potentiation of GABA transmission in the ventral tegmental area. Science 341: 1521-1525.

Borgland SL, Malenka RC, Bonci A (2004). Acute and chronic cocaine-induced potentiation of synaptic strength in the ventral tegmental area: electrophysiological and behavioral correlates in individual rats. J Neurosci 24: 7482-7490.

Chaudhury D, Walsh JJ, Friedman AK, Juarez B, Ku SM, Koo JW et al (2013). Rapid regulation of depression-related behaviours by control of midbrain dopamine neurons. Nature 493: 532-536.

Chow DK, Groszer M, Pribadi M, Machniki M, Carmichael ST, Liu $\mathrm{X}$ et al (2009). Laminar and compartmental regulation of dendritic growth in mature cortex. Nat Neurosci 12: 116-118.

Christian DT, Wang X, Chen EL, Sehgal LK, Ghassemlou MN, Miao JJ et al (2017). Dynamic alterations of rat nucleus accumbens dendritic spines over 2 months of abstinence from extended-access cocaine self-administration. Neuropsychopharmacology 42: 748-756.

Costa-Mattioli M, Monteggia LM (2013). mTOR complexes in neurodevelopmental and neuropsychiatric disorders. Nat Neurosci 16: 1537-1543.

Dadalko OI, Siuta M, Poe A, Erreger K, Matthies HJ, Niswender K et al (2015). mTORC2/rictor signaling disrupts dopaminedependent behaviors via defects in striatal dopamine neurotransmission. J Neurosci 35: 8843-8854.

Dayas CV, Smith DW, Dunkley PR (2012). An emerging role for the mammalian target of rapamycin in "pathological" protein translation: relevance to cocaine addiction. Front Pharmacol 3: 13.

Ding S, Matta SG, Zhou FM (2011). Kv3-like potassium channels are required for sustained high-frequency firing in basal ganglia output neurons. J Neurophysiol 105: 554-570.

Dong Y, Nestler EJ (2014). The neural rejuvenation hypothesis of cocaine addiction. Trends Pharmacol Sci 35: 374-383.

Dong Y, Saal D, Thomas M, Faust R, Bonci A, Robinson T et al (2004). Cocaine-induced potentiation of synaptic strength in dopamine neurons: behavioral correlates in GluRA(-/-) mice. Proc Natl Acad Sci USA 101: 14282-14287.

Dumitriu D, Rodriguez A, Morrison JH (2011). High-throughput, detailed, cell-specific neuroanatomy of dendritic spines using microinjection and confocal microscopy. Nat Protoc 6: 1391-1411.

Dunkley PR, Bobrovskaya L, Graham ME, von Nagy-Felsobuki EI, Dickson PW (2004). Tyrosine hydroxylase phosphorylation: regulation and consequences. J Neurochem 91: 1025-1043.

Giros B, Jaber M, Jones SR, Wightman RM, Caron MG (1996). Hyperlocomotion and indifference to cocaine and amphetamine in mice lacking the dopamine transporter. Nature 379: 606-612.

Hernandez D, Torres CA, Setlik W, Cebrian C, Mosharov EV, Tang $\mathrm{G}$ et al (2012). Regulation of presynaptic neurotransmission by macroautophagy. Neuron 74: 277-284.

Hoeffer CA, Klann E (2010). mTOR signaling: at the crossroads of plasticity, memory and disease. Trends Neurosci 33: 67-75.

Huang W, Zhu PJ, Zhang S, Zhou H, Stoica L, Galiano M et al (2013). mTORC2 controls actin polymerization required for consolidation of long-term memory. Nat Neurosci 16: 441-448. 
Huber KM, Klann E, Costa-Mattioli M, Zukin RS (2015). Dysregulation of mammalian target of rapamycin signaling in mouse models of autism. J Neurosci 35: 13836-13842.

James MH, Quinn RK, Ong LK, Levi EM, Charnley JL, Smith DW et al (2014). mTORC1 inhibition in the nucleus accumbens 'protects' against the expression of drug seeking and 'relapse' and is associated with reductions in GluA1 AMPAR and CAMKIIalpha levels. Neuropsychopharmacology 39: 1694-1702.

James MH, Quinn RK, Ong LK, Levi EM, Smith DW, Dickson PW et al (2016). Rapamycin reduces motivated responding for cocaine and alters GluA1 expression in the ventral but not dorsal striatum. Eur J Pharmacol 784: 147-154.

Kaspar BK, Vissel B, Bengoechea T, Crone S, Randolph-Moore L, Muller R et al (2002). Adeno-associated virus effectively mediates conditional gene modification in the brain. Proc Natl Acad Sci USA 99: 2320-2325.

Laplante M, Sabatini DM (2012). mTOR signaling in growth control and disease. Cell 149: 274-293.

Liu QS, Pu L, Poo MM (2005). Repeated cocaine exposure in vivo facilitates LTP induction in midbrain dopamine neurons. Nature 437: 1027-1031.

Liu X, Chen Y, Tong J, Reynolds AM, Proudfoot SC, Qi J et al (2016). Epac signaling is required for cocaine-induced change in AMPA receptor subunit composition in the ventral tegmental area. J Neurosci 36: 4802-4815.

Luikart BW, Schnell E, Washburn EK, Bensen AL, Tovar KR, Westbrook GL (2011). Pten knockdown in vivo increases excitatory drive onto dentate granule cells. J Neurosci 31: $4345-4354$.

Luo YX, Han H, Shao J, Gao Y, Yin X, Zhu WL et al (2016). mTOR signalling in the nucleus accumbens shell is critical for augmented effect of TFF3 on behavioural response to cocaine. Sci Rep 6: 27895.

Mameli M, Balland B, Lujan R, Luscher C (2007). Rapid synthesis and synaptic insertion of GluR2 for mGluR-LTD in the ventral tegmental area. Science 317: 530-533.

Mameli M, Halbout B, Creton C, Engblom D, Parkitna JR, Spanagel R et al (2009). Cocaine-evoked synaptic plasticity: persistence in the VTA triggers adaptations in the NAc. Nat Neurosci 12: 1036-1041. Mazei-Robison MS, Koo JW, Friedman AK, Lansink CS, Robison AJ, Vinish $\mathrm{M}$ et al (2011). Role for mTOR signaling and neuronal activity in morphine-induced adaptations in ventral tegmental area dopamine neurons. Neuron 72: 977-990.

Neasta J, Barak S, Hamida SB, Ron D (2014). mTOR complex 1: a key player in neuroadaptations induced by drugs of abuse. $J$ Neurochem 130: 172-184.

Nestler EJ (2013). Cellular basis of memory for addiction. Dialogues Clin Neurosci 15: 431-443.

Nirenberg MJ, Chan J, Pohorille A, Vaughan RA, Uhl GR, Kuhar MJ et al (1997). The dopamine transporter: comparative ultrastructure of dopaminergic axons in limbic and motor compartments of the nucleus accumbens. J Neurosci 17: 6899-6907.

Pan B, Hillard CJ, Liu QS (2008). Endocannabinoid signaling mediates cocaine-induced inhibitory synaptic plasticity in midbrain dopamine neurons. J Neurosci 28: 1385-1397.

Saal D, Dong Y, Bonci A, Malenka RC (2003). Drugs of abuse and stress trigger a common synaptic adaptation in dopamine neurons. Neuron 37: 577-582.
Saddoris MP, Sugam JA, Cacciapaglia F, Carelli RM (2013). Rapid dopamine dynamics in the accumbens core and shell: learning and action. Front Biosci (Elite Ed) 5: 273-288.

Shi X, Miller JS, Harper LJ, Poole RL, Gould TJ, Unterwald EM (2014). Reactivation of cocaine reward memory engages the Akt/ GSK3/mTOR signaling pathway and can be disrupted by GSK3 inhibition. Psychopharmacology (Berl) 231: 3109-3118.

Steffensen SC, Svingos AL, Pickel VM, Henriksen SJ (1998). Electrophysiological characterization of GABAergic neurons in the ventral tegmental area. J Neurosci 18: 8003-8015.

Sutton LP, Caron MG (2015). Essential role of D1R in the regulation of mTOR complex 1 signaling induced by cocaine. Neuropharmacology 99: 610-619.

Tavazoie SF, Alvarez VA, Ridenour DA, Kwiatkowski DJ, Sabatini BL (2005). Regulation of neuronal morphology and function by the tumor suppressors Tsc1 and Tsc2. Nat Neurosci 8: 1727-1734.

Ungless MA, Magill PJ, Bolam JP (2004). Uniform inhibition of dopamine neurons in the ventral tegmental area by aversive stimuli. Science 303: 2040-2042.

Ungless MA, Whistler JL, Malenka RC, Bonci A (2001). Single cocaine exposure in vivo induces long-term potentiation in dopamine neurons. Nature 411: 583-587.

Vialou V, Feng J, Robison AJ, Ku SM, Ferguson D, Scobie KN et al (2012). Serum response factor and cAMP response element binding protein are both required for cocaine induction of DeltaFosB. J Neurosci 32: 7577-7584.

Wang X, Luo YX, He YY, Li FQ, Shi HS, Xue LF et al (2010). Nucleus accumbens core mammalian target of rapamycin signaling pathway is critical for cue-induced reinstatement of cocaine seeking in rats. J Neurosci 30: 12632-12641.

Weston MC, Chen H, Swann JW (2012). Multiple roles for mammalian target of rapamycin signaling in both glutamatergic and GABAergic synaptic transmission. J Neurosci 32: 11441-11452.

Wu J, McCallum SE, Glick SD, Huang Y (2011). Inhibition of the mammalian target of rapamycin pathway by rapamycin blocks cocaine-induced locomotor sensitization. Neuroscience 172: 104-109.

Xiong Q, Oviedo HV, Trotman LC, Zador AM (2012). PTEN regulation of local and long-range connections in mouse auditory cortex. J Neurosci 32: 1643-1652.

Yorgason JT, Espana RA, Jones SR (2011). Demon voltammetry and analysis software: analysis of cocaine-induced alterations in dopamine signaling using multiple kinetic measures. J Neurosci Methods 202: 158-164.

Yu F, Zhong P, Liu X, Sun D, Gao HQ, Liu QS (2013). Metabotropic glutamate receptor I (mGluR1) antagonism impairs cocaineinduced conditioned place preference via inhibition of protein synthesis. Neuropsychopharmacology 38: 1308-1321.

Yuan T, Mameli M, O'Connor EC, Dey PN, Verpelli C, Sala C et al (2013). Expression of cocaine-evoked synaptic plasticity by GluN3A-containing NMDA receptors. Neuron 80: 1025-1038.

Zhong P, Liu X, Zhang Z, Hu Y, Liu SJ, Lezama-Ruiz M et al (2014). Cyclin-dependent kinase 5 in the ventral tegmental area regulates depression-related behaviors. J Neurosci 34: 6352-6366.

Zoncu R, Efeyan A, Sabatini DM (2011). mTOR: from growth signal integration to cancer, diabetes and ageing. Nat Rev Mol Cell Biol 12: $21-35$.

Supplementary Information accompanies the paper on the Neuropsychopharmacology website (http://www.nature.com/npp) 